\title{
Hypokalemic periodic paralysis
}

INSERM

\section{Source}

INSERM. (1999). Orphanet: an online rare disease and orphan drug data base.

Hypokalemic periodic paralysis. ORPHA:681

Hypokalemic periodic paralysis (hypoPP) is characterised by episodes of muscle paralysis lasting from a few to 24-48 hours and associated with a fall in blood potassium levels. 